\title{
Raymond Adams: A Life of Mind and Muscle by Robert Laureno
}

\author{
Oxford University Press, \$55, ISBN 978-0195379082
}

\author{
Eelco F. M. Wijdicks
}

Published online: 12 June 2009

(C) Humana Press Inc. 2009

Like many others, I passed through Massachusetts General Hospital. Those years completely changed my outlook on Neurology and in particular, Neurocritical Care. I attended Raymond Adams conferences and later interviewed him in order to reconstruct the development of the "Harvard Criteria" for brain death, he single handily wrote. I therefore looked forward to this biography expecting it would give me more insights in the history of Neurology at Massachusetts General Hospital.

Laureno has done something quite novel in a medical biography mixing narrative and interviews (approximately 50), but the book also includes original memos and lectures that brings the reader back to a glorious time of neuropathological discovery. The book also discusses French and German Neurology. This gem of a book explains in great detail not only Ray Adams' contributions, but also described his mentality of hard work and his drive to consistently work on clinical research. As noted by one of the interviewees "they never seem to leave the building."

Raymond Adams his contributions to the field of coma or Neurocritical Care for that matter are legendary. Original descriptions of hepatic encephalopathy, anoxic- ischemic encephalopathy (Lance-Adams syndrome), syndrome of basilar artery occlusion, embolism as a cause of stroke, and brain death are his, to name a few.

Adams wrote many classic monographs. I did not know that Principles of Neurology (now in a 9th edition rewritten by Ropper and Samuels) was a spinoff of the Neurology section of Harrison's Principles of Internal Medicine. Because the section on neurology was extensive, the editors whimsically called it "Principles of Internal Medicine with the details of Neurology."

But Raymond Adams was more than a prolific writer, this biography also evokes his days as a superb clinician aspiring so many residents and fellows. He did what so few do; writing the work and give others more credit. The book show the importance of mentoring, the value of case discussions and bedside teaching of neurology. It has many spectacular examples.

This absorbing book looks at a great neurologist. After reading this book any neurointensivist is encouraged to go back to Raymond Adam's work and study it carefully. It is there where many areas of our field originated. But there is more, it also a treatise of academic stewardship.
E. F. M. Wijdicks ( $\square)$

Mayo Clinic, Rochester, MN, USA

e-mail: wijde@mayo.edu 